University of Wollongong

Research Online

Faculty of Education - Papers (Archive)

Faculty of Arts, Social Sciences \& Humanities

7-11-2011

\title{
Uni-Start: a peer-led orientation activity designed for the early and timely engagement of commencing university students
}

\author{
Sarah E. O' Shea Dr \\ Sarah Elizabeth O'Shea, sarah.oshea@curtin.edu.au \\ Michelle Vincent \\ University of Newcastle
}

Follow this and additional works at: https://ro.uow.edu.au/edupapers

Part of the Education Commons

\section{Recommended Citation}

O' Shea, Sarah E. Dr and Vincent, Michelle: Uni-Start: a peer-led orientation activity designed for the early and timely engagement of commencing university students 2011.

https://ro.uow.edu.au/edupapers/1173

Research Online is the open access institutional repository for the University of Wollongong. For further information contact the UOW Library: research-pubs@uow.edu.au 


\title{
Uni-Start: A peer-led orientation activity designed for the early and timely engagement of commencing university students
}

Please see separate word document for authors' details

\begin{abstract}
Universities have both social and cultural contexts and new students need to participate effectively in both in order to succeed in this environment. With ever increasing numbers of students and also, the diversity of the contemporary university population, institutions have to consider innovative ways to effectively engage individuals. In terms of supporting students, there is a need to be more proactive, initiating structures of support that reach out to students rather than an often implicit expectation that the learners themselves will take the initiative and seek out support individually. This article reflects upon one approach to supporting diverse student populations that was offered in an Australian university. The approach is based upon a 'community of practice' (Lave \& Wenger, 1991) model, where newcomers are offered a 'safe' place to practise new skills and articulate new roles with little risk, providing access to more experienced members of the community and also, authentic settings. The article highlights the format of the program, the theoretical basis and also, summarises the successive evaluations.
\end{abstract}

\section{Introduction}

There is a clear need for new students to be effectively coached in the organisational culture of the university in a timely and efficient way. Most universities operate under tight time constraints, semester teaching weeks are limited and for new students, it is necessary to cover a great deal of subject material as well as come to terms with what has been referred to as the 'hidden curriculum' (Bourdieu \& Passeron, 1977). The transition to university study can be likened to other cross-cultural experiences as students are expected to master an alien language and environment where requirements often remain tacit and somewhat invisible (Lawrence, 2005). Some of the expectations presumed both prior to arrival at university and during the initial stages of study, may remain hidden or unexplained for certain groups. Hence, the onus largely falls on the university institution to accommodate those students positioned outside the 'traditional' cohort, particularly those who may have had little contact with the university environment or who have had a significant gap in their educational participation. 
Based on the recognition that universities need to better prepare students for the university environment, a university transition program was designed to address those 'gaps' in knowledge and understanding as identified by students themselves. The Uni-Start: Transition to Study program was initiated in 2007. The difference between this and other orientation programs is that it is grounded within the actual experience of students. Similar to Lave and Wenger's (1991) concept of 'community of practice', Uni-Start draws on the experiences of the experts within the university community to provide the skills and knowledge necessary for the 'novice' or newcomer to cope with this new environment. The focus of this paper is to chart the development and design of this program, highlighting both the theoretical and practical underpinnings and also describe how it was received and evaluated by participants.

\section{Literature review}

\section{Background}

The massification or widening participation agenda common in most developed countries, means that academic expectations of the first year student need to be revised in order to consider the burgeoning diversity of this student cohort. The ‘worldwide phenomenon' of mass participation is demonstrated by the huge increase in global enrolments, now constituting over 150 million worldwide, an increase of 53\% in one decade (Altbach, 2010). This increase in numbers is often heralded as offering positive outcomes for students as well as benefits for institutions and nations. For the individual learner, access to university provides the opportunity to improve social mobility and increase financial stability. Institutionally, more students can augment funding levels and for the country or nation state such mass participation offers advances in skills and knowledge levels. However, 'opening the door' to university does not guarantee success in this environment and with increasingly diverse student populations, new approaches and perspectives are required to make sure that this 'open door' does not simply become a 'revolving door' (Blythman \& Orr, 2001-2002, p232)

A better recognition of the qualities and skills that students are now bringing to the university environment needs to be conceptualised as well as a renegotiation of academic expectations and learning behaviours. Issues surrounding independent learning and the nature of engagement 
within the academic community need to be made explicit. Having studied how organisational structures impact on withdrawal behaviour, Berger and Braxton (1998) conclude that institutions can implement quite basic strategies to aid student retention. Their findings include the need for universities to employ clear communication concerning academic standards and expectations. This requisite need is echoed by Martinez and Munday's (1998) research which was based on a survey of thirty-three British colleges of further education. The participants in this latter study included staff and students with both groups expressing how clear advice prior to enrolment is necessary in order to ensure a match between student expectations and realities. Such clarity is also required in relation to communicating institutional rules or what Trow (1975) refers to as the 'private life' of university; the 'moment-by-moment, day-by-day activities and interactions' (p113) within this environment.

\section{The university marketplace and the new student}

Such explicitness should extend to material and information produced about the institution. In an increasing economic driven marketplace, universities are required to essentially sell their wares and some of the promotional material may not reflect reality. Watson, Cavallaro-Johnson and Austin (2004) highlight how student perceptions of their chosen program and profession can influence decisions around withdrawal or persistance. This research examined a cohort of students studying Education, indicating an unrealistic perception of the teaching role had a negative impact on retention. These authors discovered a 'considerable gap between their [students'] idealism and realism of the class-room' (p68) and suggest that university retention practices and also promotional material needs to realistically portray the chosen study and profession. How best to prepare students for this environment remains illusive, already most commencing students are inundated with printed material before commencing but how much of this is absorbed or even understood is unclear.

This situation is further complicated by the market-driven nature of the higher education sector, which situates the student as client, and where establishing a brand is imperative to institutions who are struggling to claim a segment of a shrinking market (Krause, 2005). As White (2007) highlights, this process is also determined by the global nature of the education sector: 
Consumers of 'educational product' are actively recruited on the world stage, particularly as full fee paying international students provide a much needed injection of funding. (p594)

Bruning (2002) applies public relations theorisation in order to understand the nature of student connectedness. Focusing on 'organisation-public relationships' (p39), Bruning suggests that individuals who perceive that they are engaged in a relationship with an institution are more inclined to remain as customers, indicating that a focus on relationship building with students can perhaps translate positively in terms of retention. In such relationships, Bruning (2002) identifies the need not only to communicate with those involved in the relationship but additionally to make those individuals feel valued. Berger and Braxton (1998) also emphasise the importance of this relationship building and highlight how students' participation in the decision making process on campus can facilitate and contribute to such feelings of value. Thus, arguably the nature of the relationship between the institution and the student has clear implications for, and influences on, learner's behaviour and decisions.

In an increasingly mass system of education, the difficulties associated with creating and maintaining communication with students are clear. The learners themselves frequently have a number of competing demands for their time and some may not spend a huge amount of time on campus. This can mean that creating and sustaining relationships with peers may not be a priority or a possibility. Equally, for teaching staff, larger classes means that students may be one face in many, particularly in the early stages of their degree program, only in the latter years emerging as individuals. With this in mind, it is important that institutions themselves explore ways to assist in the creation of social networks not only to improve the social wellbeing of learners but also, their learning.

\section{Creating social networks to aid learning}

Not only does learning occur within dedicated learning spaces with knowledge imparted by learned experts; knowledge acquisition can also evolve through participation with others in social settings and informal networks. Lave and Wenger (1991) recognised the vital element of social participation in learning about and within institutions, recognising that individuals learn by being placed in social relations with others rather than only in formalised class based environments. As Lave and Wenger highlight the 'curriculum is available to newcomers 
through their increasing participation (with others) in the relevant and inevitable structured social practices (activities, tasks, habits) of the community' (Fuller, 2007, p19). In this way, learning is conceived as a 'collective, relational and...social practise' (p19).

A community of practice is built upon the idea of shared understandings that characterise an environment, much of which is not taught formally. For example, ways of doing things or presenting oneself; certain language or terminologies (Wenger, 1998), are all elements that convey membership. While Lave and Wenger were particularly concerned with workplace learning, the shifting character of university environments, the need to create early and sustainable relationships with new students and the increasing isolation of students means that this theory has much to offer higher education institutions. While traditionally, universities are built upon a model of didactic instruction, the teacher or lecturer being the expert with the student positioned as the novice or the learner, the increasing numbers and diversity of the student population means that this model is no longer viable.

Within the Australian higher education sector, the increasing distance and lack of contact between students and staff has been noted in the research literature. The latest Australian Survey of Student Engagement (ACER, 2010), highlights how significant numbers of students have never received 'timely' feedback from their teachers and have only had limited opportunity to meet or have contact with teaching staff outside of class or course requirements. This sense of isolation is also highlighted in the Australian longitudinal study of the first year experience, the fourth and latest survey revealing how a lower percentage of students 'believe one of their teachers knows their names' or indicate 'an interest in their progress' when compared with the 2005 survey results (James, Krause \& Jennings, 2010, p1).

However, this sense of isolation and disjuncture in universities is not limited just the Australian location, instead Altbach (2010) highlights how globally this ‘mass higher education' system has led to a 'poorer learning environment for students' (p3). This situation is augmented by the diversity of the student body, some of whom will have had little exposure to university culture or academic conventions. Mann (2001) argues that most new university students can be likened to a 'colonised' subject (p.11), faced with the conflict of trying to create a bridge between prior 
experience and the new world of knowledge they are entering. Misinformation may be derived from indirect information sources such as friends or family; thus setting up a mismatch between student expectations and institutional structures, invariably resulting in a level of friction and dissonance. This isolation can only be increased for those that attend a campus characterised by a 'commuter culture', where students come to lectures and then have to rush off to other commitments; in this case time spent on campus is diminished considerably.

The experience of assimilating to the university environment can be likened to negotiating membership to a 'community of practice'. Lave and Wenger (1991) emphasise the inherently social nature of learning, their 'theory of situated learning' highlights how learning involves participating in social practice and how newcomers to this environment are both assimilating and being assimilated by this community. The term community is not neutral and should not be assumed to connotate commonality but rather perceived as a 'dynamic' space complete with 'tensions' and ‘contradictions' (Quinn, 2005, p.8). The concept of community embraces both social and physical contexts, within which new students will need to participate effectively. Wenger (1998) points out that involvement in this community can be negotiated around how learners perceive their competence and that such perceptions inform their identity formation.

The following sections outline a program that was established in order to situate commencing students within a community of practice. New students were placed within a social context and the knowledge they brought with them was foregrounded and celebrated. The Uni-Start: Transition to University program sought to prepare students for the realities of study by creating a social learning network with more experienced students. Uni-Start relies on authentic and contextualised resources and sources of information, which ultimately serve to reveal the cultural tools embedded within the university environment.

\section{Uni-Start: context and participants}

As mentioned previously, the Uni-Start program has been offered since 2007 on an annual basis and more recently on a bi-annual basis. The campus where this program is available is located in a region recognised as being economically and socially disadvantaged. Over fifty percent of the population in this area left school with no formal education qualifications (Australian Bureau of Statistics [ABS] , 2001-2006). Statistics also reveal a much lower percentage of residents who have completed a university degree ( $6 \%$ compared with $16 \%$ for the state) or completed the final 
year of high school (26\% compared to $42 \%$ for the state) (ABS, 2001-2006). The low participation and success of certain equity groups within the Australian tertiary landscape has been recognised (James, 2004) and interview research conducted with first in family students (O’Shea, 2007; 2007a) reveals 'gaps' in students' knowledge and also a lack of preparedness for the university environment upon arrival. Hence, the development of Uni-Start was based upon the need to address the mismatch in expectations of low socio-economic (SES) students by grounding the content and structure of the program firmly within actual student experience.

The student population at this campus whilst relatively small $(n=3,000)$ is still highly diverse. Over half the population is categorised as mature aged (over the age of 21) many of these students have had a significant gap in their education and often have used alternative forms of entry to obtain a university place. This includes the university's access program, which provides a university admissions ranking for entry upon completion. The campus also has a significant number of students who identify as first in the family to attend university, although this data is presented anecdotally as prior to 2010, statistics were not collected on educational status of family or parents. During the time that Uni-start was offered, it attracted between $10 \%-15 \%$ of the commencing student population at the Campus, with more than $60 \%$ of the participants having identified as receiving pensions or social security support.

\section{Why Uni-Start - Transition to Study?}

The Uni-Start program is modeled upon a similar strategy offered at James Cook University (Calder, 2003) and is based upon a democratic approach to assisting students. Its design is inclusive with participants encouraged to learn in a socially situated context by using both each other and the peer facilitators. This systematic and individualized approach assists in both socialising new students into the university culture and also engaging individuals by providing situated learning based on real-life experiences.

The major strength of Uni-Start is that ownership of the program lies with the student facilitators, all of whom are students themselves bt more advanced in their degree program. This overarching framework influences, motivates and inspires students to engage in the University environment on academic and social levels. Indeed, reflections from student participants indicate the influence of the student facilitators as inspiration to 'maybe one year do the same to 
help others'. The democratic nature of Uni-Start is characterised by inclusivity, providing a 'safe' place for commencing students to learn from each other and peer facilitators. This peer-led transition program utilises experiential, situated learning activities, building upon a constructivist approach which recognises the need for learning to be situated within the environment where these new skills and knowledge will be used. The facilitators actual model and replicate the strategies that have assisted their own personal success, acting as 'guides' to the new students who actively construct their own understanding of the university. In their evaluations, respondents mentioned that the inclusion of student perspectives/narratives in the program further resonated with them as this was actual 'lived experience'.

The learning is situated within a community of practice, with the objective of revealing tacit knowledge and shared understandings. The student facilitators are responsible for the content of the program so this enables university culture and expectations to be defined from a student perspective, reflecting knowledge that was actually lacking upon arrival rather than what is presumed to be lacking. The novices, or new students, engage in meaningful dialogue with the experts, or those students who are more advanced in their degree program, again this is characteristic of a 'community of practice'. By encouraging collaboration with peers and validating the knowledge and skills that the participants bring with them to this educational setting, the intent of Uni-Start is to locate the 'novice' and 'expert' in a reciprocal relationship with each party learning from the other. This approach recognises how within a learning community or network, each participant can learn from each other regardless of experience in the environment and that learning relationships do not need to be hierarchical in nature.

One key aspect of the program is dedicated to exploring what Fuller and Unwin (2004) term as the 'learning territories' of individuals, which consists of the 'range of regions in which the individual has had the opportunity to learn and gain expertise' (cited in Fuller, 2007, p25). This activity encourages the new students to reflect upon the skills and knowledge that they bring to the university environment. This type of activity is particularly important to the more mature students who may have spent time raising a family or juggling work with other time pressures. The student facilitators then assist in translating these within the context of the university teaching and learning environment. This particular strategy also validates the learning acquired in settings outside of the formal educational environment. This type of validation and recognition 
can be particularly important for those commencing students who have limited or negative educational experience or those who have accessed university from non-traditional forms of access.

Brookfield (1991, p44) describes the importance of assisting new university students to overcome a perceived 'imposter syndrome' where individuals may feel a sense of not belonging or not deserving of university study. This is particularly the case for those students who may not have considered attending university or who may have little exposure to this environment. UniStart attempts to negate this 'imposter syndrome' by positioning beginning students as having knowledge thus empowering participants to recognise the skills that they bring to this learning experience.

\section{Planning for Uni-Start}

As mentioned, the premise of the Uni-Start program is that it is designed and developed by the student facilitators, however prior to this planning occurring, it is necessary to both recruit the facilitators and provide training. The recruitment process is a competitive one where applicants are requested to submit a short statement (500 words) explaining why they are interested in being involved in the program. These statements provide a very successful gauge of the level of enthusiasm and commitment held for the program, both of these qualities are vital for its successful implementation.

Once accepted, the facilitators are asked to attend a half-day of training, which provides an introduction to adult learning principles, an overview of existing university support services and also techniques around group facilitation. One of the most important aspects of this training is that participants are offered the opportunity to reflect upon their first year of university and what they wished they had known at commencement. This brainstorming activity provides the basis for the Uni-Start program and at the culmination of the training session, the group start to plan the program and allocate tasks / sections amongst the group.

Each year the program for Uni-Start is modified as new student facilitators redesign activities or focus depending on the previous year's feedback. However, a typical day of activities includes a mix of social activities and those designed to develop academic skills. The social activities include ice breaker activities to breakdown social barriers, campus scavenger hunts to aid 
geographical orientation and also, trivia type activities based on campus insider knowledge. Over the years, student facilitators have also elected to include short presentations on managing time, note-taking, navigating university terminology, essay writing and oral presentation skills, The emphasis in these sessions is very much on what new students need to know upon arrival and informed by what had worked for student facilitators, lending further legitimacy to the content.

All sessions included within Uni-Start utilise authentic materials as the facilitators provide examples of personal study planners, essay plans and notes, therefore, providing participants with real, relevant resources for learning and succeeding at University. These types of authentic learning experiences are personally relevant and when situated within appropriate social contexts can assist new students to develop appropriate and effective understandings, thereby increasing intrinsic motivation (Stein, Isaacs \& Andrews, 2004). The sessions orientate the students to the campus geographically and also culturally through the inclusion of academic panels and guest speakers. The student facilitators also foreground their own narratives, which normalises possible difficulties, for example, how to decipher assignment cover sheets or university terminology. The benefits of Uni-Start are multi-faceted in that the participants are engaged and inspired to develop habits and abilities to successfully engage at the University, while the student facilitators gain valuable experience that directly assists in the development of their own professional graduate attributes, such as team work, communication, and leadership.

Since 2007, Uni-Start has been evaluated annually by both the student participants and the student facilitators, the data generated is then used to develop and refine the program for the following year. The following section details the nature of these evaluations and the response that has been received from participants.

\section{Evaluations and Feedlback}

Gaining feedback from both facilitators and participants enables multiple individual perspectives to contribute collectively to the future direction and development of Uni-Start. Each session within the two day program is designed to account for a variety of commencing students' needs, and the opportunities for first-year students to share their concerns and ask questions is integral to their level of engagement and satisfaction with their university experience. 
In 2007, the evaluation was completed by 77 students and indicated that more than $95 \%$ of the students were either satisfied or very satisfied with the structure and presentation of the sessions, while 60 students 'strongly agreed' that the program had a clear relevance to their first-year studies. In 2008, the evaluations were completed by 104 students and again students were both satisfied with the course with $91 \%$ of respondents perceiving attendance as 'very beneficial' to their first-year experience. When the open questions were analysed, it became clear that students appreciated the blend of academic skills combined with social interaction. Such sentiments were clearly expressed in response to the question: What did you find the most useful aspects of the course?

Being able to ask questions, meeting other students and comparing how we felt about starting uni (2007).

Thank you for giving first time students the opportunity to orientate, associate with other first timers, meet concerns and needs, a taste of what's to come... (2008)

In addition to evaluation forms, in 2009 follow-up phone interviews were conducted with UniStart participants a few months after completing the program. All the interviewees regarded the program as providing a positive start to their academic career with particular reference to the social networking opportunities and increase in confidence. All respondents stated that they would recommend the program to future commencing students. In providing this 'taster' of university, student participants were able to develop confidence and motivation in a supportive environment, characterised by stories of success and achievement from the student facilitators. As one student explained the sessions enabled 'students to ask questions' and this provided reassurance about being able to succeed in this environment. In addition, a number of student participants mentioned how helpful it was to have their fears recognised, as one participant explained, it was helpful to hear that '...everyone is in the same boat of uncertainty, discovering that everyone has the same fears...' while references to university being 'less daunting' were also prevalent.

Early exposure to the university culture via the student voice and perspective provides a more realistic assessment of the teaching and learning environment, arguably improving student 
engagement and experience. Indeed, written evaluations of Uni-Start in 2009 from student participants indicate that 96\% either 'strongly agreed' or 'agreed' that:

- all aspects of the program were of benefit to their transition into university studies;

- the material that was covered was clear and concise;

- the course was well-planned and organized; and

- the facilitators were knowledgeable.

The impact on student experience and engagement is also indicated by the open comments. The most common areas of feedback include how 'approachable' and 'friendly' the facilitators were, and how after participating in the program commencing students felt more 'relaxed' or 'less anxious' about starting their university studies. In addition, most participants comment that they themselves intend to 'help with Uni-Start' in the future.

Reflective reviews written by individual student facilitators also highlighted the personal and public impacts derived from creating and facilitating this program. These written reflections highlight how involvement not only provided marketable skills but also describe how this experience provided an opportunity to 'give back' to the university community. This was an unexpected outcome of the program and highlights that while some students may be juggling a number of competing responsibilities and have limited time, there are still those who desire to actively engage with the university environment and need opportunities to do so. Peer-led programs such as Uni-Start facilitates this type of participation and as one facilitator reflects:

'the Uni-Start program allowed me to really express to a handful of students the enthusiasm I have for the Campus and for studying.'

Similarly, another student facilitator explained how participating 'had been a wonderful journey' and 'enabled me to see just how capable I really am ... [providing] ....me with the opportunity to acquire professional skills valued by the University, the community and employers.' The student facilitators bring an enthusiasm to the delivery of this course, which serves to further motivate the student participants and socialise them into the university environment.

At the culmination of each Uni-Start program, facilitators are also invited to participate in a debriefing focus group, to provide individual reflections about the program and suggestions for the following year. The points raised at this meeting are recorded by the team and then provided to 
the following year's facilitators who use this as a basis for that year's program. This process enables the program to remain student-driven providing reflective, on-going quality assurance directed by the facilitators rather than university staff. In the most recent de-brief, the reflections of the student facilitators indicated that their involvement was both rewarding and satisfying. Some of the skills that they had developed included 'team work, organising, planning and presenting', 'leadership skills' and 'discover[ing] how much I have learned...since I started my own journey'. The most rewarding aspect of their participation was described as the realisation that they contributed in a positive way 'to the experience of the new students', and assisted in 'reducing the anxiety of being alone'.

The evaluation data also provides the future direction for this program. Both the 2007 and 2008 evaluations revealed a need for more discipline-specific information with $16 \%$ of the respondents mentioning the need for more Faculty input. In response to this, a series of short presentations were conducted with Faculty staff to explain the program and offer assistance if a Faculty version of the program was to be introduced. In 2008/2009, Uni-Start was adopted by the Faculty of Business and Law, and in 2010, the program was rolled out across the University with each Faculty developing a particular Uni-Start program with the assistance of student mentors.

\section{Implications for practise}

For those adult learners who are returning to education after a significant gap or who have few formal educational qualifications, the student-centred nature of the program offers a nonthreatening way of exploring this new educational environment. From an administrative or institutional perspective, the relative ease with which this program can be initiated makes it an appealing choice. While student facilitators will require some institutional support around fundamental processes such as room bookings or invitations to staff, the design and delivery of the program lies with the students themselves. The following points are provided to assist those readers interested in introducing the program within their institution and are designed to provide guidance based on the authors' experiences:

- Payment of Facilitators: Don't assume that payment is necessary as a number of the facilitators expressed how they were willing to be involved in this initiative on a voluntary basis. However, having said that we did offer a gift in the form of book 
vouchers, this served to not only assist their studies but also, did not affect Social Security payments they may have been receiving.

- Ownership: The ownership of the program lies with the students, which also means that the responsibility around organisation lies there as well. If activities are planned then it is important to make it clear that the group will be responsible for implementing / coordinating these.

- Demonstration: Providing an opportunity for the student facilitators to present an abbreviated program to staff and interested parties prior to the actual delivery day, enables feedback and suggestions to be obtained. Ideally, this should occur in the location where the student facilitators will be presenting to the new students i.e. the lecture hall or classroom.

- Employability: A short statement / dot points concerning the skills that the facilitators have demonstrated in relation to their involvement in the program, can be a valuable asset to a curriculum vitae or future job application.

Aside from these practical considerations, involvement with this type of programs also benefits those of us employed within the education sector, enabling us to remain aware of who are students are and also mindful of the reality of their student experience.

\section{Conclusion}

Peer interaction and networks undoubtedly aids the transition and retention of first-year students (Kantansis, 2000; Yorke \& Thomas, 2003). However, the Uni-Start program furthers the reach of the peer relationships by creating a community of practice where new students are provided with a space to both reflect upon the skills they bring to the environment and hear from the 'experts' on how best to succeed in this environment. Ultimately, the students themselves have ownership of this program and this characteristic ultimately provides the authenticity needed for this approach to be successful.

This Uni-Start program was directly informed by the needs of the unique student cohort at the campus, many of these students are older and the first in their family to come to university. 
Creating a 'safe' environment where such students can articulate new roles with little risk and practise skills in an authentic context are the key characteristics of this approach. The emphasis on cooperative learning further enhances students' self esteem and, in turn, motivates students to participate in the learning process and positively impacts the student experience. Cooperative efforts among students result in a higher degree of accomplishment by all participants, and where students help each other, this cooperation builds a supportive community that raises the performance level of each student involved (Panitz, 1998). 


\section{$\underline{\text { References }}$}

ACER. (2010). Doing More for Learning: Enhancing Engagement and outcomes. Australasian Survey of Student Engagement. Victoria: ACER

Altbach, P. (2010). Access means inequality [Electronic Version]. International Higher Education. Retrieved 7th April 2010, from http://www.bc.edu/research/cihe.html

Australian Bureau of Statistics (2004). Socio-economic indexes for electoral divisions: 2001 Census (2003 boundaries). Retrieved 6 May, 2008 from http://www.aph.gov.au/library/Pubs/cib/2004-05/05cib01.htm

Berger, J. B., \& Braxton, J. M. (1998). Revising Tinto's Interactionalist Theory of Student Departure through theory elaboration. Research in Higher Education, 39(2), 103 - 119.

Blythman, M., \& Orr, S. (2001-2002). Joined up policy: a strategic approach to improving retention in the UK context. Journal of College Student Retention, 3(3), 231-242.

Bourdieu, P., \& Passeron, J. C. (1977). Reproduction in Education, Society and Culture. London: Sage Publications

Brookfield, S. (1991). The Skillful Teacher: on technique, trust and responsiveness in the classroom. San Francisco: Jossey Bass.

Bruning, S. D. (2002). Relationship building as a retention strategy: linking relationship attitudes and satisfaction evaluations to behaviour. Public Relations Review (28), 39 - 48.

Calder, A. (2003). Peer Interaction in the Transition Process. Unpublished manuscript.

Fuller, A. (2007). Critiquing theories of learning and communities of practice. In J. Hughes, N. Jenson \& L. Unwin (Eds.), Communities of Practice - Critical Perspectives (pp. 17 - 40). New York: Routledge.

James, R. (2004). Socio-economic Background and Higher Education Participation: An analysis of school students' aspirations and expectations. Canberra: AGPS.

James, R., Krause, K., \& Jennings, C. (2010). The first year experience in Australian Universities Findings from 1994 - 2009. Melbourne The University of Melbourne.

Kantanis T. (2000). The role of social transition in student's adjustment to the first year of university. Retrieved 4 September, 2003, from http://www.adm.monash.edu.au/transition/research/kantansis3.html

Krause, K. L. (2005, 5-7 September ). Keynote Paper: The changing of student experience: Who's driving it and where is it going? Paper presented at the Student Experience Conference: Good 
Practice in Practice, Charles Sturt University, Wagga Wagga, NSW.

Lave, J., \& Wenger, E. (1991). Situated Learning: Legitimate Peripheral Participation. Cambridge: Cambridge University Press.

Lawrence, J. (2002, 8-10 July). The 'deficit-discourse' shift: university teachers and their role in helping first year students persevere and succeed in the new university culture. Paper presented at the 6th Pacific Rim First Year in Higher Education Conference 2002: Changing Agendas - Te Ao Hurihuri, University of Canterbury, Christchurch, New Zealand.

Mann, S. (2001). Alternative Perspectives on the student experience: alienation and engagement. Studies in Higher Education, 26(1), 7 -19.

Martinez, P., \& Munday, F. (1998). 9,000 Voices: Student Persistence and Dropout in Further Education. London: Further Education and Development Agency.

O' Shea, S. E. (2007). Well I got here..but what happens next? Exploring the early narratives of first year female students who are the first in the family to attend university. Journal of Australian and New Zealand Student Services Association (29), 36-51.

O' Shea, S. E. (2007a). Exploring the Early expectations and ambitions of First Generation Female students with an Australian University. Student Affairs West, 26(2), 16-19.

Panitz, T. (n/d). Benefits of Cooperative Learning in relation to student motivation [Electronic Version]. Retrieved 7th April 2010, from http://home.capecod.net/ tpanitz/tedsarticles/motivation.htm

Quinn, J. (2005). Belonging in a learning community: The re-imagined university and imagine social capital. Studies in the Education of Adults, 37(1), 4 - 17.

Stein, S., Isaacs, G \& Andrews,T (2004). Incorporating authentic learning experiences within a university course. Studies in Higher Education 29,(2), 239 - 258.

Trow, M. (1975). The public and private lives of higher education. Daedalus, 2, 113-127.

Watson, G., Cavallaro-Johnson, G., \& Austin, H. (2004). Exploring relatedness to field of study as an indicator of student retention. Higher Education Research and Development, 23(1), 57 - 72.

Wenger, E. (1998). Communities of Practice: Learning, Meaning and Identity. Cambridge: Cambridge University Press.

White, N. (2007). 'The customer is always right?': Student discourse about higher education in Australia. Higher Education, 54, 593 - 604.

Yorke, M., \& Thomas, L. (2003). Improving the retention of students from lower socio-economic 
groups Journal of Higher Education, Policy and Management 25(1), 63 - 74. 